\title{
Preauricular Angioleiomyoma
}

\author{
II Ha Moon ${ }^{1}$, Su Sie Chin ${ }^{2}$ and Moo Kyun Park ${ }^{1}$ \\ ${ }^{1}$ Departments of Otorhinolayngology-Head and Neck Surgery, ${ }^{2}$ Pathology, Bucheon Hospital, Soonchunhyang University \\ College of Medicine, Bucheon, Korea
}

Received July 31, 2012

Revised November 28, 2012

Accepted November 30, 2012
Preauricular masses are commonly seen in the otology clinic. Excisional biopsy is essential for diagnosis, and treatment is necessary to reduce the risk of malignancy and for cosmetic purposes. We recently treated a rare case of angioleiomyoma of the preauricular area. Angioleiomyoma is a benign tumor arising from smooth muscle within blood vessel walls. These tumors can arise anywhere in the body; however, they are usually found in the lower extremities and present as a painful mass. Angioleiomyoma of the preauricular area in an elderly person is rare, and only a few cases have been reported. Here, we report the case of an 85-year-old male patient with angioleiomyoma of the preauricular area and provide a literature review.

Korean J Audiol 2012;16:138-140

KEY WORDS: Angioleiomyoma · Elderly · Preauricle.

\section{Introduction}

Preauricular masses are commonly seen in the otology clinic. Several benign or malignant tumors are found in the preauricular area; however, preoperative diagnosis of a preauricular mass presents a challenge. The differential diagnosis includes benign skin tumor, congenital cyst and fistula, temporomandibular joint cystic lesion, and malignant tumor. ${ }^{1-4)} \mathrm{Al}-$ though the most preauricular mass lesions are benign, surgical excision is necessary to reduce the risk of malignancy and for cosmetic purposes. ${ }^{5)}$

Angioleiomyomas are rare benign neoplasm of the soft tissue. ${ }^{4,6-8)}$ They occur primarily in the lower and upper extremities. ${ }^{4)}$ Although angioleiomyomas have been described in the head and neck region, a few cases of auricular angioleiomyoma, including the helix, pinna, external auditory canal, and lobule, have been reported. ${ }^{9-11)}$ An angioleiomyoma in the auricular area has been reported in fewer than $3 \%$ of 562 total cases. ${ }^{4}$ Herein, we describe angioleiomyoma of the preauricular area and present a literature review.

\section{Case Report}

An 85-year-old man presented to the Department of Otolar-
yngology-Head and Neck Surgery at our hospital with hearing difficulty in his left ear. Pure tone audiometry showed left sensorineural hearing loss. During the physical examination of the ear, a small round cystic mass was found on the left preauricular area (Fig. 1). It did not hurt and was not tender. The patient had noticed the mass about 6 months previously and it had grown slowly. No similar lesion was found on his body. His medical and family histories were unremarkable.

After informed consent was obtained, the lesion was completely excised under local anesthesia in the operation room for differential diagnosis and cosmetic purposes. Grossly, the specimen was a $1.4 \times 1.0 \times 0.7 \mathrm{~cm}$ firm, spherical mass with a white-gray, solid cut surface. Microscopic examination revealed that the tumor was a well-defined nodule of smooth muscle bundles containing thick-walled blood vessels (Fig. 2). No significant cellular atypia or mitotic activity was observed. Based on histological findings, the pathologic diagnosis of venous type angioleiomyoma was made. No evidence of a recurrence was observed 6 months after surgery.

\section{Discussion}

Angioleiomyoma is a subtype of leiomyomas. They are benign, smooth muscle tumors that arise from the tunical media 
layer of blood vessels. ${ }^{7,8)}$ Angioleiomyomas are classified into three histological subtypes: capillary or solid, venous, and cavernous. $^{4,8)}$

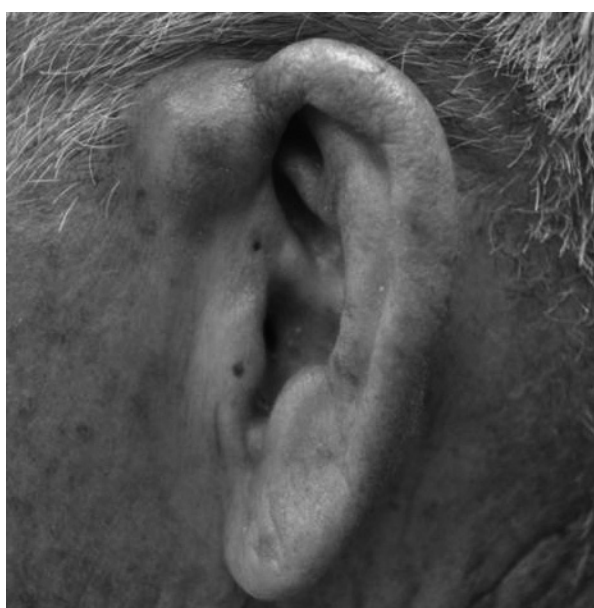

Fig. 1. Preoperative photomicrograph of the $1.5 \mathrm{~cm}$ round, cystic mass in the left preauricular area.
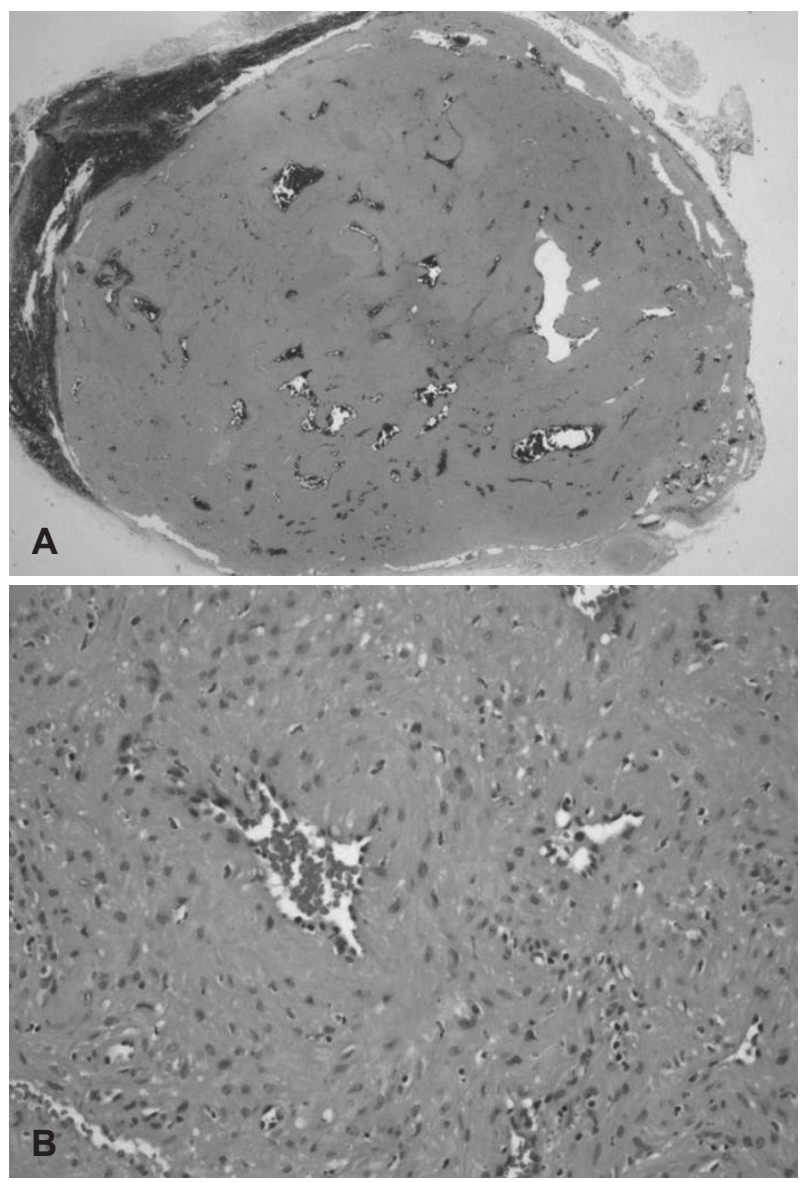

Fig. 2. A: The tumor is a well-defined nodule composed of smooth muscle bundles with dilated, thick-walled blood vessels [hematoxylin and eosin (H\&E), $\times 10]$. B: The vessels of the tumor have thick muscular walls and the muscle in the vascular wall blends with the intervascular smooth muscle bundles. The smooth muscle cells are mature and well differentiated without cytologic atypia $(H \& E, \times 200)$.
An angioleiomyoma can occur anywhere on the skin or in the subcutaneous tissue; however, the most common sites are the lower extremities (67\%), upper extremities (22\%), head and neck (8.5\%), and trunk (2.5\%). ${ }^{4}$ Solid angioleiomyomas occur most frequently in the lower extremities of women. The venous type tumor most frequently appears on the head and neck region and is generally found in men. ${ }^{4,6,8)}$

The tumors usually present as small, solitary, round, firm masses that are skin-colored and enclosed in a capsule., ${ }^{4,8,12)}$ There was no specific clinical presentation of angioleiomyoma. About half the patients with angioleiomyoma subjectively complained of pain and tenderness. ${ }^{4,8,12,13)}$ Pain can be induced by exposure to wind, cold, local pressure, and other imperceptible stimuli. Interestingly, tumors occurring in the head and neck regions are usually not accompanied by pain. ${ }^{4,12,13)}$ The mass in our case was not painful or tender. Angioleiomyomas commonly present between the third and sixth decades of life. ${ }^{4,8)}$ The mass in our case developed, unusually, in the patient's seventh decade.

Diagnosis is based on an excisional biopsy because an angioleiomyoma is not easily differentiated from other subcutaneous tumors by clinical presentation or gross apperance. ${ }^{3,12)}$ The tumors are well circumscribed, glistening, white-gray nodules on gross appearance. ${ }^{1,10,12)}$ Microscopically, the tumors have the same characteristic appearance. ${ }^{7,8,12)}$ Smooth muscle bundles and the vascular channels are surrounded by a thin capsule. The pathological differential diagnosis for perivascular cell tumors are need. ${ }^{4,6-8,14)}$ Various stains are used to identify vascular leiomyomas. ${ }^{4,7,8,12)}$

Recurrence after excision was reported in 2 of 562 patients. ${ }^{4}$ However, cases of malignant changes and an association with a leiomyosarcoma have been reported. ${ }^{15)}$

The present case report describes an angioleiomyoma arising from the preauricle. This lesion should be considered in the differential diagnosis of mass-like lesions of the preauricular area.

\section{REFERENCES}

1) Lomeo PE, McDonald JE, Finneman J. Temporomandibular joint cyst as a preauricular mass. Am J Otolaryngol 2000;21:331-2.

2) Nicollas R, Guelfucci B, Roman S, Triglia JM. Congenital cysts and fistulas of the neck. Int J Pediatr Otorhinolaryngol 2000;55:117-24.

3) Sharma M, Khachemoune A. What is this slow-growing preauricular lesion? JAAPA 2011;24:20.

4) Hachisuga T, Hashimoto H, Enjoji M. Angioleiomyoma. A clinicopathologic reappraisal of 562 cases. Cancer 1984;54:126-30.

5) Padgett JK. Cutaneous lesions: benign and malignant. Facial Plast Surg Clin North Am 2005;13:195-202, v.

6) Wang CP, Chang YL, Sheen TS. Vascular leiomyoma of the head and neck. Laryngoscope 2004;114:661-5.

7) Argenyi ZB, Piette WW, Goeken JA. Cutaneous angiomyolipoma. A light-microscopic, immunohistochemical, and electron-microscopic 
study. Am J Dermatopathol 1991;13:497-502.

8) Ramesh P, Annapureddy SR, Khan F, Sutaria PD. Angioleiomyoma: a clinical, pathological and radiological review. Int J Clin Pract 2004; 58:587-91.

9) Choe KS, Sclafani AP, McCormick SA. Angioleiomyoma of the auricle: a rare tumor. Otolaryngol Head Neck Surg 2001;125:109-10.

10) Kim HU, Mun JH, Park SH, Yun SK, Ihm CW. Angioleiomyoma on the helix of the ear. J Dermatol 2004;31:858-9.

11) Picciotti PM, Cantore I, La Greca C, Di Nardo W, Scarano E. Angioleiomyoma of the external auditory canal. Am J Otolaryngol 2007; 28:235-7.
12) Citıl R, Ciralik H, Gül A, Sayar H. Auricular angioleiomyoma: a case report. Turk Patoloji Derg 2011;27:268-70.

13) Wirth GA, Sundine MJ, Kong AP, Carpenter PM. Auricular angioleiomyoma: a case report and review of the literature. Ear Nose Throat J 2007;86:281-3.

14) Nall AV, Stringer SP, Baughman RA. Vascular leiomyoma of the superior turbinate: first reported case. Head Neck 1997;19:63-7.

15) Herren DB, Zimmermann A, Büchler U. Vascular leiomyoma in an index finger undergoing malignant transformation. J Hand Surg Br 1995;20:484-7. 